Doctor en Educación, Artes y Humanidades de la Facultad de Filosofía y Letras por parte de la Universidad Autónoma de Chihuahua, México. Sus investigaciones abordan temas sobre fotografía, cuerpo y sociedad. Maestro en Artes por la Facultad de Artes de la UACH y Licenciado en Diseño Gráfico por la Universidad Icel. Actualmente, miembro del Sistema Nacional de Investigadores de Ciencia y Tecnología. Además, imparte las materias de mercadotencia digital y diseño gráfico en la Universidad Tecnológica de Chihuahua. Colaborador del Cuerpo Académico con las líneas de investigación: Mercadotecnia-Investigación de mercados y Publicidad en la uтch. En la Universidad La Salle de Chihuahua, es docente de la materia de semántica en la maestría de publicidad. En licenciatura imparte fenomenología, metodología y fotografía. Beneficiario del programa: Fondo Municipal para Artistas y Creadores, conducido por el Instituto de Cultura del Municipio de Chihuahua con el proyecto Chihuahua en el tiempo; compendio de fotografías de edificios históricos.

Historial editorial

Recepción: 22 de marzo de 2021

Revisión: 26 de marzo de 2021

Aceptación: 29 de mayo de 2021 Publicación: 28 de junio de 2021 


\title{
Violencia publicitaria de moda en contra de la diversidad corporal. La necesidad en México de una Ley Antiphotoshop
}

\author{
Fashion advertising violence against body \\ diversity. The need in Mexico for an \\ Antiphotoshop Law
}

\section{Violência na publicidade de moda contra a diversidade corporal. A necessidade no México de uma lei anti-photoshop}

\author{
Juan Pablo Méndez Moreno \\ Universidad La Salle Chibuahua \\ jpablomm@gmail.com
}

\section{Resumen}

La violencia hacia la aceptación de la diversidad del cuerpo se presenta en la mayoría de la publicidad, una propaganda que homogeniza y estereotipa tanto a los modelos que utiliza como al receptor de sus mensajes, dejando un angosto marco de apreciación sobre la forma corpórea. El presente texto tiene como objetivo argumentar, justificar y comprobar la necesidad de implementar la "Ley Antiphotoshop" en las fotografías publicitarias de moda en México como medida preventiva e inicial para lograr que los receptores, lectores, tengan una reflexiva interpretación sobre las alteraciones y ediciones realizadas en las fotografías de moda que se exponen en los sitios o formatos públicos o virtuales que se utilizan para la proyección de estas imágenes. La metodología utilizada para el presente trabajo es el cruce teórico para lograr la sustentabilidad argumentativa sobre la violencia hacia la forma diversa corporal. Se concluye que la aplicación de esta norma pueda fomentar en los individuos una apreciación personal y social que excluya la estandarización de las características que componen un cuerpo estereotipado ayudando a mejorar la autoestima.

Palabras clave: Ley antiphotoshop, Publicidad, Moda, Cuerpo, Fotografía editada, Violencia gráfica 


\section{Abstract}

Violence towards the acceptance of the diversity of the body is presented in most advertising, a propaganda that homogenizes and stereotypes both the models it uses and the recipient of its messages, leaving a narrow framework of appreciation on the corporeal form. The objective of this text is to argue, justify and verify the need to implement the "Antiphotoshop Law" in fashion advertising photographs in Mexico as a preventive and initial measure to ensure that recipients, readers, have a thoughtful interpretation of alterations and editions made in the fashion photographs that are exposed in the public or virtual sites or formats that are used for the projection of these images. The methodology used for the present work is the theoretical crossroads to achieve argumentative sustainability on violence towards the diverse body form. It is concluded that the application of this norm can foster in individuals a personal and social appreciation that excludes the standardization of the characteristics that make up a stereotyped body, helping to improve self-esteem.

\section{Keywords: Anti-photoshop law, Advertising, Fashion, Body, Edited photography, Graphic violence}

\section{RESUMO}

A violência para a aceitação da diversidade do corpo é apresentada em grande parte da publicidade, uma propaganda que homogeneiza e estereotipou tanto os modelos que usa quanto o destinatário de suas mensagens, deixando um estreito quadro de apreciação sobre a forma corporal. O objetivo deste texto é argumentar, justificar e verificar a necessidade de implementar a "Lei Anti-photoshop" nas fotografias de publicidade de moda no México como uma medida preventiva e inicial para garantir que os destinatários, leitores, tenham uma interpretação criteriosa das alterações e edições feitas na moda fotografias que são expostas em sites públicos ou virtuais ou formatos que são usados para a projeção dessas imagens. A metodologia utilizada para o presente trabalho é a encruzilhada teórica para alcançar a sustentabilidade argumentativa sobre a violência contra as diversas formas corporais. Conclui-se que a aplicação dessa norma pode promover nos indivíduos uma valorização pessoal e social que exclui a estandardização das características que compõem um corpo estereotipado, ajudando a melhorar a autoestima.

Palavras-chave: Lei anti-photoshop, Publicidade, Moda, Corpo, Fotografia editada, Violência gráfica 


\section{INTRODUCCIÓN}

La moda ha sido un fenómeno social que se involucra en diversos sentidos en nuestra vida cotidiana. En gran medida, su efectividad depende de la publicidad y a su vez, esta estriba de la comprensión o persuasión del mensaje cuando llega al receptor.

Esto ha causado que la industria de la moda sea un anómalo social que provoca gran interés en el terreno de la investigación, análisis que parten de sus mensajes, enfocados desde diversas disciplinas, reflexiones que se centran en lo filosófico y documentos variados que permiten definir ciertas consecuencias sicosociales que se relacionan a la conducta de los individuos en diferentes épocas.

La medicina también ha mostrado interés sobre problemáticas que se originan principalmente entre los jóvenes y correlacionadas a la publicidad de la moda que derivan en enfermedades como anorexia, depresión o bulimia (Shaw, 1995), y no solo eso, sino asimismo complicaciones que se ligan al pensamiento ideológico y personalidad, aceptación o rechazo entre los individuos (Jobling, 1998), así como diferenciaciones económicas que fisuran y dividen a las sociedades provocando problemas de autoestima.

La moda, erigida en un tradicionalismo arcaico sobre el género y el cuerpo, promueve una apreciación y valoración corporal binaria: hombre - mujer-. Así mismo, utilizando a Butler, diremos que los cuerpos inteligibles son los que se apegan a la normatividad social que regula nuestra corporalidad, nuestro género y nuestra sexualidad y los no inteligibles son anormales, función que cumple la moda en prácticamente toda su publicidad.

La medida de lo inteligible, apegada a la norma social, produce una serie de parámetros estéticos que van desde, peso, altura, etnia, color de ojos, cabello en tipo y distribución, proporciones corpóreas de brazos, piernas, órganos sexuales y sobre todo el cumplimiento de la simetría. La moda enfatiza estas características como únicas según sus parametros discriminando a toda aquella diversidad corpórea.

La violencia que se ejerce en estos simples ejemplos es sobre la idoneidad de lo que se debe ser, no hay una publicidad que exhiba ya que la moda siempre intenta tener seguidores, decirnos como deberíamos ser o de vernos y si no es así, deberíamos intentarlo (Berger, 1972).

Como lo mencionó el autor, la envidia y el glamour son subjetividades que utiliza la publicidad para embelesar sus mensajes (1972). La propaganda trabaja sobre el empobrecimiento del intelecto y conduce el pensamiento hacia lo abstracto sobre conceptos como la belleza. 
Esta industria produce productos de vestimenta, bisutería, perfumería y otros (principalmente) y estos se relacionan directamente con factores culturales como: calidad de vida, Life style, nivel económico, edad, género, roles sociales, actividades profesionales y de ocio, sexualidad y otros. La moda, no puede dejar de ser un factor de gran relevancia que se inmiscuye con la creación y el desarrollo de personalidad y con las relaciones humanas, es una forma de presentarte diariamente al mundo, una forma de ser un ser social.

El cuerpo, se ha convertido en un elemento configurable que se aleja de su carácter metafísico, un elemento de manipulación que subyace a la carga simbólica relacionada con la vestimenta. Calefato, menciona que la vestimenta es un dispositivo que nos permite configurar el mundo en el que nos encontramos, una relación directa entre signos y sentidos, una forma que nos permite ser sensibles al mundo. La vestimenta no se trata solo de una característica sígnica que vestimos todos los días sino de una compleja maraña que manifiesta un lenguaje no verbal, un "simulacro de existencia" que se basa en una edición del cuerpo que acoge, tatuajes, colores, formas del cabello; adornos que construyen una sintaxis sociocultural (Calefato, 2001, p213-16) una correlación entre la ropa, los adornos, las ediciones o alteraciones del cuerpo como extensiones de orejas, tinta sobre el cuerpo, implantes subdérmicos para manifestar nuestra simpatía con una moda o marca.

$\mathrm{El}$ argumento de la autora sumado al anterior que define la inseparable unidad de vestido-cuerpo y la propia concepción que esto produce, genera no solamente una apreciación personal y social, sino una estructura pensamiento reduccionista que somete nuestra diversidad corporal como algo "anormal" y la conduce hacia la idea fisionómica estereotipada sobre el cuerpo publicitario.

Por otra parte, hablando de los signos que menciona Calefato y para involucrar a la semiótica, la parte sígnica de la vestimenta que menciona Barthes incurre en la compleja estructura social. Para el autor, vestir es un signo que articula la parte sintáctica del cuerpo y la vestimenta (2003) aunque la operatividad de las cargas sociales simbólicas, no trabajan en solitario o de una manera aislada, sino en conjunto con los demás sistemas que permiten la aparición de un aparato social más enredado que podemos denominar sociedad operante.

(...) ... el conjunto de imágenes del cuerpo vestido se produce mediante estrategias intertextuales apoyadas por varios sistemas de signos y de comunicación, desde la fotografía al periodismo especializado, la música, la cultura metropolitana, la informática, el diseño, los sistemas audiovisuales y, por último, pero no por ello menos importante, el cine (Calefato, 2001, p.216). 
Cualquiera de los medios de comunicación masiva activos en nuestra sociedad, someten el pensamiento diverso, analítico y crítico sobre lo corpóreo a una violencia visual obnubilada de referencias ineluctable que aparecen en cada espacio físico o digital, definiendo un pensamiento inconsciente de valores cohesivos únicamente al estereotipo en boga; lo que conlleva a conclusiones sobre que un cuerpo que se encuentra fuera de estos parámetros, deberá asimilarse como poco estético o bello por mencionar solo algunos adjetivos, al margen de lo regulatorio y aprobado socialmente.

Una de las medidas regulatorias a la que todos los humanos tenemos derecho, es al conocimiento de sabernos frente a fotografías manipuladas que se utilizan en la propaganda de la moda. Estas imágenes siguen robusteciendo un sistema de fantasía sobre lo corpóreo, el género, las actitudes que debemos asimilar, la concepción sobre la juventud, la sexualidad y tantas otras acepciones que se embeben en el sistema fenoménico de la moda en relación con la sociedad y la autoconcepción de identidad como reflejo de lo social. A diferencia de otros países, en México todavía no contamos con un sistema de prevención de engaño a los consumidores, lectores de las imágenes de moda.

\section{Necesidades aCtUAles PARA Fortalecer la No Violencia GRÁFICA}

En este momento, es necesario aplicar una reforma en las instituciones correspondientes para la exposición de publicidad que implique a las fotografías publicitarias de moda que se exhiben en: espacios públicos o medios propagandísticos ya sean físicos o digitales, a través de la modificación de las leyes que gestionan la exposición de estos instrumentos comunicativos por medio de la Procuraduría Federal del Consumidor (profeco) para enunciar la frase "Imagen alterada y/o retocada digitalmente" en las fotografías que lo ameriten obligando a los anunciantes a ser responsables sobre el uso de edición en los cuerpos y gestos faciales que se exhiben en estos medios.

Con lo anteriormente escrito, ¿creemos indispensable implementar la ley antiphotoshop en las fotografías publicitarias de moda México?, ¿nos encontramos en un momento políticosocial en el que es posible incorporar Ley Antiphotoshop en México? Los beneficios que aportaría la inserción de la frase a los anuncios publicitarios que se exponen en espacios públicos, lograría que los individuos fueran más sensibles a las repercusiones y a la asimilación de los cuerpos alterados que en ellas se exhiben, comprendiendo que la publicidad enajena e 
incentiva hacia un conocimiento del propio cuerpo que es erróneo, produciendo un pensamiento sobre nosotros que se inicie de la no comparación con estereotipos de belleza establecidos.

Implementar la Ley Antiphotoshop en la publicidad en México, en las imágenes que lo amerite o usen el cuerpo humano como objeto de publicidad, a través del organismo de la PRofeco u otras instituciones que regulen el uso de la exposición publicitaria por los diferentes medios de comunicación masiva, facultaría a los individuos a ampliar su margen de apreciación sobre que el cuerpo y el rostro que se presenta como "perfecto" es en realidad una imagen manipulada para colocar un ideal que conduce al consumo y cambios significativos de conducta, incluso amerita la desaprobación del propio cuerpo y rostro si es que tiene diferencias a esa imagen publicitaria.

\section{Argentina, Francia y Estados Unidos}

En el marco regulatorio de publicidad establecido en Buenos Aires Argentina por el Senado Bonarense, el 2 de septiembre del 2017 se aprovo una "Ley Antiphotoshop" que busca limitar la incidencia que tienen los estereotipos y cánones de belleza que rigen las figras icónicas populares en los medios masivos principalmente en las fotografías publicitarias (Los Andes Periodísmo de verdad, 2017).

La leyenda con la que deberán contar es "esta imagen ha sido retocada y/o modificada digitalmente”. Así los argentinos se defienden contra la violencia simbólica, como la han nombrado. En la defensa argumentativa que permitió que esta ley se aprobara, se estableció como singularidad que la "irrealidad" con la que construyen estas fotografías en las intervenciones digitales por parte de los programas de cómputo, proyectan cuerpos con parámetros de belleza que causan frustración al no poder asemejarse a ellos (Ídem).

Una vez aprobada la ley, se ha declarado que la regulación aplica para publicidades de referencia estéticas que se encuentren en los espacios públicos y las que aparecen en diferentes canales virtuales como redes sociales, páginas web u otros medios impresos o diigales (Los Andes Periodísmo de verdad, 2017).

En estudios realizados sobre belleza, moda, bondad y otros atributos relacionados con los estereotipos expuestos en la propaganda, se ha encontrado que tienen más impacto en la edad adolescente (Snyder et al., 1977). La relación directa que tienen estas fotografías con los espectadores impactan de tal manera que "las consecuencias se reflejan en enfermedades de desórdenes alimenticios que se estima afectan entre el 0,5 y el 3 por ciento de mujeres en el mundo, mani- 
festó la legislador" (Los Andes Periodísmo de verdad, 2017). Entre las singularidades que destacaron para la defensa del uso aplicativo de la ley, se manifestó que la exageración del uso de retoque y alteraciones corporales y del rostro, ponen en relieve el engaño al consumidor, así como referencia a temas polémicos en cuestión de discriminación y perspectiva de género.

La ley no solo se propicia en Buenos Aires, sino en todo el territorio de este país. La Secretaría de Derechos Humanos de la Provincia será la encargada de las sanciones y multas que se basarán en las Leyes Nacionales No 22.802, de Lealtad Comercial, y No 24.240, de Defensa del Consumidor (Ídem).

En otra investigación similar en el año 2014, se encontró que, en Estados Unidos ya estaba promoviendo la idea de una "Ley de la autoestima" que tiene sus raíces en este país con la autora Jean Kilbourne y su serie de documentales educativos denominados "Killing us softly: Advertising's Image of Woman" que cristalizan la relación entre imágenes publicitarias con los desórdenes aliemtnarios, violencia contra la mujer, principalmente y sexismo entre otros (Rodríguez y Vestisca 21).

En una nota digital periodística mencionan que el 11 de octubre del 2017 en Francia, se ha incluido en la regulación de los anuncios publicitarios sobre la violencia simbólica expuesta o proyectada en los anuncios publicitarios, específicamente en la moda. De acuerdo con las cifras, indican que en Francia es el segundo país de la Unión Europea en donde habitan más personas que están por debajo de su peso apropiado. Además, se estima que los trastornos alimenticios afectan a unos 600 mil jóvenes de las cuales $66.66 \%$ tienen anorexia siendo la segunda causa de mortalidad en personas que oscilan entre los 15 a 24 años (Infobae, 2017).

La norma implementada, se dirige principalmente a prohibir exponer imágenes publicitarias de modelos alteradas digitalmente intentando aparentar un peso diferente del real (Ídem).

En México la institución encargada de verificar la publicidad es la Profeco (Procuraduría Federal del Consumidor). Esta organización se ampara bajo la Ley Federal de Protección al Consumidor del artículo 32. De acuerdo con dicha Ley, La Profeco define que a la publicidad como un instrumento que "alude al modo de promoción, a través de la cual el proveedor-anunciante que el consumidor-destinatario de la misma conozca, se motive y decida sobre la consumición de sus bienes, productos y servicios" (PROFECO, 2006).

Dentro del marco de definición de la publicidad comercial, este organismo subraya dos principales finalidades: la primera como informativa la cual tiene como característica que: 
Informa al receptor sobre la existencia y características de un bien, producto o servicio que se quiere vender; y 2, la Persuasiva que tiene como distinción: Impulsar al receptor para que actúe en el sentido que sugiere el mensaje publicitario, normalmente a la adquisición de ese bien, producto o servicio. En este sentido, el artículo 32 de la Ley, prohíbe a los proveedores la difusión de publicidad engañosa. Se les impone el deber de difundir publicidad veraz, comprobable y exenta de textos, diálogos, sonidos, imágenes, marcas, denominaciones de origen y otras descripciones que induzcan o puedan inducir a error o confusión, por engañosas o abusivas (PROFECo, 2006).

Partiendo de la anterior especificación que hace el instituto, señala que la publicidad engañosa induce al error por la manera inexacta, falsa, exagerada, parcial, artificiosa o tendenciosa en que se presenta. Como parte de su objetivo que se ponen en relieve de manera implícita en la declaración del artículo 32, indica que: "la publicidad debe contribuir a elevar la cultura del consumo entre la población” y que, por ello, deberá ser comprobable que su intensión hacia el consumidor es de buena fe y que, además, estos elementos le ayuden a tomar una decisión racional sobre su consumo (Ídem).

La señalización sobre el procedimiento de análisis de la publicidad comercial, la PROFEco aclara que se requiere de esfuerzos interpretativos y por esta razón, deja al margen criterios filológicos para buscar criterios más amplios que atiendan a descubrir significados jurídicos para el mundo de destinatarios al que está dirigido. En la misma declaración de Ley, se señala que la PROFEco tiene la capacidad de conocer sobre asuntos de información y publicidad de conformidad con la Ley de acuerdo al ordenamiento legar que se establece en el artículo $1^{\circ}$ en donde se estipula como segundo principio "ii La protección contra la publicidad engañosa y abusiva en el abastecimiento de los bienes, productos y servicios" (PROFECO, 2006).

Así mismo, se entiende como publicidad engañosa por este organismo la que hace una referencia a información o características relacionadas con algún servicio, bien o producto y que puedan no ser verdades, o bien que induzcan a un error o confusión por presentarse de manera artificiosa, inexacta, falsa, tendenciosa, exagerada o parcial. De acuerdo con este criterio de distinción, se clasifican en:

a) Publicidad engañosa por acción b) Publicidad engañosa por omisión c) Publicidad comparativa engañosa d) Publicidad denigratoria e) Publicidad parasitaria o adhesiva f) Publicidad encubierta g) Publicidad exagerada o exageración publicitaria.

A su vez, y en relación con los intereses propuestos en este texto, se señalan dos principales que incurren en la fotografía publicitaria de moda: 
La publicidad engañosa por acción de bienes, productos y servicios consiste en incluir textos, diálogos, sonidos, imágenes, marcas, denominaciones de origen y otras descripciones que induzcan o puedan inducir a error o a confusión.

La publicidad engañosa por omisión es aquella que silencia características del bien, producto o servicio indispensables para que el consumidor pueda contar con la información apropiada para decidir, ya que ante su ausencia la decisión del consumidor estará viciada por la inexactitud del mensaje publicitario. Este tipo de publicidad no dice algo que de informarlo al consumidor haría que éste decidiera por no adquirir el bien, producto o servicio objeto de la publicidad (PROFECO, 2006).

Como último, punto sobre esta Ley, es preciso mencionar que, aunado a lo anterior, se agrega, para este fin, la publicidad denigratoria y la encubierta que se especifica como:

(...) es la que provoca descrédito de un bien, producto o servicio ajeno (publicidad denigratoria profesional o de producto). En este caso, la publicidad será ilícita o engañosa cuando la información no sea veraz, por lo que debe estimarse abusiva ya que inducirá al consumidor a cambiar sus hábitos de consumo de manera ilícita. La publicidad encubierta es una modalidad de publicidad engañosa y recibe el calificativo de "encubierta" precisamente porque con ella se pretende ocultar su carácter publicitario, tratándose de una publicidad oculta bajo un velo informativo por medio del cual se intenta hacer creer (confundir) al consumidor que están ante un mensaje informativo de carácter objetivo, no viciado por el interés persuasivo y subjetivo que caracteriza al mensaje publicitario (Ídem).

\section{LAS PROBLEMÁTICAS DE LA IMAGEN PUBLICITARIA DE MODA}

En este apartado se irán exponiendo de una manera breve y concisa las diferentes problemáticas en torno a la imagen de moda, gracias a haber sido estudiadas en la investigaciones anteriores, se establece que es preciso contar con un sistema que permita la interpretación del mismo de una manera sencilla y específica para revalorar, cuando sea el caso, que la imagen que tienen ante ellos ha sido alterada y que la representación de la persona que se plasma en la imagen, es producto de una falsa representación basada en prototipos corporales establecidos por la industria de la moda.

La fotografía, no de manera general sino en su aplicabilidad en la moda, ha sido, hasta el momento, un objeto basto de interrogantes que ponen en cuestión: la visión y la representación del individuo, la sectorización social, la clase económica, las preferencias raciales, la sexualidad, el género, los patrones conductuales correspondientes al estereotipo, la intervención al cuerpo, la apreciación del cuerpo como materia de cambios y más. 
Por estas razones, es imprescindible transitar brevemente sobre cada una de las interrogantes que se derivan de la imagen fotográfica publicitaria de moda y así concluir con la necesidad de implementación de una frase que señale la alteración de las imágenes publicitarias, resguardándose tras una Ley que trastoque a la publicidad y delimite su actuación, salvaguardando la integridad mental y física de sus ciudadanos.

Como se ha precisado en investigaciones anteriores, la fotografía en su incursión en la moda ha estado presente en los espacios públicos desde 1892 (Méndez y Rico Bovio, 2018), inició con publicación en revistas en Paris Francia, como punto de partida para después colocarse en todo el mundo y no sólo en las publicaciones periódicas de formatos pequeños como la revista, sino en diversos sitios públicos $\mathrm{y}$ a veces en los espacios íntimos.

Este dispositivo de comunicación gráfica, motiva a la adopción de las representaciones sociales por medio de los estereotipos y prototipos corporales, compuestos — principalmente- bajo criterios de la industria de la moda. Pero esta apreciación de belleza, según la moda en boga, se construye con singularidades corpóreas y rostros alterados por el maquillaje, operaciones quirúrgicas e intervenciones con la manipulación digital en la posproducción en las fotografías, así cada una de ellas, supone problemáticas distintas y de diferente envergadura (Méndez y Rico Bovio, 2018).

Aunado a la problemática de la homogenización, en numerosos estudios se ha demostrado la relación de enfermedades como la anorexia y bulimia, entre otras, especialmente en los adolescentes por la significativa imposición publicitaria tras la asimilación de los estereotipos y prototipos corporales denominados como estéticos y bellos (Soley-Beltran, 2010).

Otra preocupación que discurre, es la manera en la que asimilamos nuestra presentación física, se encuentra regulada por modelos canónicos de belleza, actúan sobre el yo indicando la manera en que nos relacionamos con los demás seres sociales; es un principio controlador de la forma en la que nos asimilamos a nosotros mismos y a los demás en un determinado contexto social (Zambrini, 2010). Así mismo, sus experiencias se ven reguladas por este principio de la apariencia que se principia y finaliza en la publicidad de la moda. Marcas de representación mundial como: Dolce \& Gabbana, Calvin Klein, Levi's, Carolina Herrera, Polo Ralph Laurent, Yves Saint Laurent, Michael Kors, Tommy Hilfiger, Dona Karan, Louis Vuitton, Pierre Cardin, Tous, Crocs, Zara, Pull \& Bear, Zara entre otros, figuran como las principales casas de moda son las que establecen la intromi- 
sión de la moda en la sociedad (Tungate, 2008) desde estas ideologías arraigadas en lo más profundo de la sociedad.

Dentro de los hallazgos de la investigación que anteceden a esta propuesta textual, se manifestaron una serie de consecuencias de alienación y cosificación que producen las imágenes de moda (Baudri1lard, 2009; Calefato, 2004; Entwistle, 2002; Saulquin, 2014). La relación de la moda y los estereotipos con la interpretación de identidad, género, rol social, edad y asimilación de presentación y representación social, más la discriminación, la desnudes, la sexualidad, la clase social y la pertenencia a algún grupo social.

La derivación de tales problemáticas sociales subyace a la interpretación de estos "modelos" que se exponen en la foto por medio de los soportes publicitarios; es ahí en donde interviene la tecnología para la alteración de corporeidad y del rostro produciendo personas representadas (prototipos) en las fotografías de moda que se asumen como patrones de conducta íntimamente ligados al interaccionismo del photo-sharing en las redes sociales y señalan en gran porcentaje a una conducta de imitación que se origina entre usuarios comunes y los modelos que aparecen en las imágenes de moda que se han venido proponiendo a lo largo del tiempo por medio del mercadeo apropiándose de los espacios públicos y transformando el pensamiento social (Andrews, Marc van Leeuwen, Mattheis Lars van Baaren, Rickert Bart, 2016).

La industria de la moda ha utilizado a la fotografía como un conducto que permite el descenso de las producciones gráficas a la sociedad masiva, imponiendo sus preferencias ideológicas, apelando a las emociones susceptibles y sensibilizadas construidas desde principios de siglo xx (Morin, p.19) respecto a la tierra prometida - promise land - que se sustenta en una idea de la cultura de masas, la cual permite que se cree y desarrolle la persuasión a través de las campañas publicitarias, en este caso, de la industria de la moda, que por cierto no son azarosas o ingenuas, sino que siempre buscan la manera de "satisfacer"las necesidades del consumidor.

Las campañas de marketing son estudiadas de tal manera que se definen parte de los resultados que se deben obtener por parte de los anuncios publicitarios, autores como: (Andrews et al., 2016; Bauman, 2012; Eguizábal, 2001, 2009; Erner, 2010; Lipovetsky, 1987; Navarro, 2017) entre otros, han indagado al respecto y presentan resultados de sus investigaciones en un marketing de rastreo y comprensión de los ideales y fantasías de la sociedad que fomenta el consumo constante que se basifica en la idea de la felicidad obtenida por la acción de la compra y esta a su vez, está ligada a los parámetros de similitud del modelo. 
Así mismo, la problemática de la apreciación del cuerpo, se asoma para ser contemplada como un elemento de suma importancia dentro de las imágenes publicitarias de la moda; su preponderancia recae en la representación y asimilación de nosotros mismos a través de los modelos. La contemplación de un cuerpo de cierta etnia ejerce discriminación a otros grupos sociales, anteponiendo un determinado gusto o patrones de conducta que se asimilan de acuerdo con el rol de género, aunque no exclusivamente de él.

Sobre este mismo eje de discusión en torno al cuerpo, se realzan temáticas que enlazan la desnudes y la apreciación corpórea, no se sólo se trata de colocar en juicio el uso de la misma sino de reflexionar de qué manera la vestimenta cumple con una función de género, sexualidad, edad, clase social y sobre todo la desnudez (Calefato, 2004).

Amalgamando todas estas singularidades, es indispensable recapacitar y actuar sobre las exposiciones que la industria de la moda a través de la fotografía de moda comete en la sociedad, contar con un claro sistema gráfico que enlace una simbología inmediata por medio de íconos incrustados en la fotografía para definir el grado en que las fotografías han sido alteradas, es de suma importancia.

Las ediciones o intervenciones en las imágenes publicitarias de la moda, exponen información gráfica violenta que atenta contra los derechos de las personas al incurrir en estereotipos o prototipos corporales inalcanzables o irreales. Aunque este no corresponde al problema de raíz que se genera por estos medios publicitarios, si es una de las aristas que tiene graves implicaciones en el ser humano y la construcción de su identidad.

\section{Conclusiones}

Nuestro cuerpo y rostro es único, pensar en un modelo al que debemos de seguir, fomenta sentimientos de frustración; las personas expuestas en las fotografías de moda son tan perfectas que es difícil y fantasioso pensar en asemejarse a ser como ellos, o intentar seducir a una, ¿alguien las ha visto? ¿saben en donde viven o qué hacen? Parecen personas creadas digitalmente, mujeres u hombres que no se ven comúnmente en la calle para un individuo común. Sin embargo, los anuncios los vemos por doquier, en plazas comerciales, en revistas, en las redes sociales, en las series televisivas, en anuncios publicitarios de YouTube y otros medios de streaming como Amazon Prime, Netflix, нво, etc. Al fin de cuentas la industria de la moda asciende a más de 100 billones de dólares al año y según las cifras, cada uno de noso- 
tros estamos expuestos a más de 2000 anuncios por día construyendo el más poderoso sistema social educativo informal (Kilbourne, 2000, p.184).

Crecemos con programas televisivos, incluso la ideología abstracta sobre moral y ética de los programas transmitidos, en diversas ocasiones se ven reproducidos en los comportamientos de nuestros padres, hermanos, tíos, amigos, parejas y más. Conductas sobre como ser un hombre o una mujer. Como reaccionar o reconocer el rechazo, la burla o agresión a las personas de preferencia sexual distinta. También nos enseñan cómo ser atractivo, seductor, gracioso, patán, exitoso y feliz; son procedimientos que ligera, constante y agresivamente nos construyen (ibídem; Berger, 1972)

La media normativa social, origina una serie de individuos que priorizan su interés en la funcionalidad social y productiva que se limita solamente a un rango de edad en donde se puede ser participe al modelo especial en donde incluye un estereotipo de belleza y un prototipo corporal que responde a una medida de salud como un bonus. El encajonamiento de estas actividades, acciones y pensamientos condiciona a las personas a intentar ser un modelo aprobado socialmente. Existen diversos modelos dentro de los parámetros de la publicidad que suscitan singularidades que definen grupos sociales, pero no diversifican en su totalidad las formas corpóreas sino en vestimenta o actitud corporal.

Esta violencia gráfica que simplifica un sistema de comunicación publicitaria limita nuestro parámetro sobre nuestra aceptación, fomenta la burla y la discriminación a lo diferente y motiva una serie de problemas sociales que subyacen a la artificialidad de la estética que se supone es lo bello.

La necesidad creciente de contar con una Ley antiphotoshop en México, es indicada a través de una sociedad en donde las prioridades inciden en ser lo más semejante posible al estereotipo con el que sienta que tiene más probabilidades de asimilación. La educación sobre las estrategias publicitarias que conducen a la persuasión (Kilbourne, 2012), deberían de ser expuestas ante el público para alimentar una alfabetización visual y que no deje a la publicidad una serie de lagunas que no delimitan sus parámetros de exposición de mensajes enajenantes y discriminatorios sobre lo que creen que deberíamos de ver, aceptar y ser convencidos por ellos. 


\section{REFERENCIAS}

Andrews, M., van Leeuwen, M. L., \& van Baaren, R. B. (2016). Persuasión: 33 técnicas publicitarias de influencia psicológica. Gustavo Gili. https:// itunes.apple.com/mx/book/persuasión/id1109349195?mt=11

Barthes, R. (2003). El sistema de la moda y otros escritos (C. Roche (ed.)). Gustavo Gili.

Baudrillard, J. (2009). La sociedad de consumo: Sus mitos, sus estructuras (A. Bixio (ed.)). Siglo xxi de España Editores, S.A.

Bauman, Z. (2012). Vida de consumo (M. Rosenberg \&J. Arrambide (trans.)). Fondo de Cultura Economica. https://itunes.apple.com/mx/book/ vida-de-consumo/id594642003?mt=11

Berger, J. (1972). Modos de Ver. G Gili. https://itunes.apple.com/mx/book/ modos-de-ver/id1075790501?mt=11

Calefato, P. (2001). "El cuerpo vestido, los sentidos y la escritura: entre la moda y el cine". En DeSignis, 1, 213-224.

- (2004). The clothed body. Berg Publishers.

Eguizábal, R. (2001). Fotografía publicitaria. Cátedra.

-. (2009). Industrias de la conciencia: una historia social de la publicidad en España, 1975-2009. Ediciones Península. https://itunes.apple.com/ $\mathrm{mx} /$ book/industrias-de-la-conciencia/id831840132? mt=11

Entwistle, J. (2002). El cuerpo y la moda: una visión sociológica. Paidós.

Erner, G. (2010). Sociología de las tendencias/Sociologie des tendances (Issue 391). Gustavo Gili,.

Infobae. (2017). "Francia revoluciona el mundo de la moda con una 'ley anti Photoshop". En Infobae recuperado en https://www.infobae. com/tendencias/lifestyle/2017/10/11/francia-revoluciona-el-mundo-de-la-moda-con-una-ley-anti-photoshop/

Jobling, P. J. (1998). Fashion figures: word and image in contemporary fashion photography. Universitoyf Warwick.

Kilbourne, J. (2000). “Beauty... and the beast of advertising”. En Women in culture: An intersectional anthology for gender and women's studies (pp. 183-186). John Wiley \& Sons Chichester, West-Sussex.

-. (2012). Can't buy my love: How advertising changes the way we think and feel. Simon and Schuster.

Lipovets ky, G. (1987). El imperio de lo efímero: la moda y su destino en las sociedades modernas (Primera ed). Anagrama.https://www.epubgratis. org/el-imperio-de-lo-efimero-gilles-lipovetsky/

Los Andes Periodismo de verdad. (2017). "Cómo es la ley 'Anti Photoshop' que ya rige en Buenos Aires".

Méndez, M. J. P., \& Rico Bovio, A. (n.d.). "The use of the body in fashion photographs as way of learning for stereotypes in social networks”. http://orcid.org/0000-0002-6840-9625 
—. (2018). "Educación, cultura, estereotipos, cuerpo, género y diferencias sociales en la fotografía de moda". En IE Revista de Investigación Educativa de La rediech, 9 (17), 165-178.

Morin, E. (1962). El espiritu del tiempo: ensayo sobre la cultura de masas.

Navarro, G. M. (2017). Marketing y comunicación de moda. ESIC Editorial. https://itunes.apple.com/mx/book/marketing-y-comunicación-demoda/id1350224090?mt=11

Profeco. (2006). Guía de procedimientos de publicidad engañosa. https://www. profeco.gob.mx/juridico/Documentos/SSC/Normatividad_TomoIV/Publicidad engañosa.pdf

Rodríguez, C. L., \& Vestisca, M. D. B. (2014). "La imagen de la persona en los medios y su influencia en la autoestima: la importancia de la apariencia en la evaluación general de la persona”. En Revista Internacional de La Imagen, 1, 21-38.

Saulquin, S. (2014). Politica de las apariencias. Grupo Planeta Spain. https://itunes.apple.com/mx/book/política-de-las-apariencias/ id 934756929 ? $\mathrm{mt}=11$

SHAw, J. (1995). "Effects of fashion magazines on body dissatisfaction and eating psychopathology in adolescent and adult females". En European Eating Disorders Review, 3(1), 15-23.

Snyder, M., Tanke, E. D., \& Berscheid, E. (1977). "Social perception and interpersonal behavior: On the self-fulfilling nature of social stereotypes". En Journal of Personality and Social Psychology, 35(9), 656.

Soley-Beltran, P. (2010). "Cuerpos ideales. Una aproximación interdisciplinaria al estudio de los modelos de moda”. En Quaderns de l'Institut Català d'Antropologia, 26, 107-134.

Tungate, M. (2008). Marcas de moda: Marcar estilo desde Armani a Zara. Editorial Gustavo Gili, S. L.

Zambrini, L. (2010). "Modos de vestir e identidades de género: reflexiones sobre las marcas culturales en el cuerpo". En Nomadias, 11,130-149.

Este artículo se publica bajo una licencia de Creative Commons Reconocimiento-NoComercial 4.0 Internacional, y puede ser usados gratuitamente para fines no comerciales, dando los créditos a los autores y a la revista.

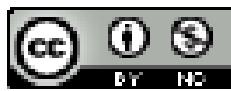

